\title{
Tatalaksana Anestesi pada Pasien Anak dengan Cystic Craniopharyngioma yang Menjalani Gamma Knife Radiosurgery
}

\author{
Monika Widiastuti*), Radian A Halimi**), Iwan Fuadi**), Sri Rahardjo ${ }^{* * *}$, Tatang Bisri***) \\ "Departemen Anestesiologi Fakultas Kedokteran Universitas Pelita Harapan, Tangerang, Indonesia \\ ${ }^{* *}$ Departemen Anestesiologi Siloam Hospitals Lippo Village, Tangerang, ${ }^{* * *}$ Departemen Anestesiologi dan Terapi \\ Intensif Fakultas Kedokteran Universitas Padjadjaran, Rumah Sakit Dr. Hasan Sadikin Bandung, Departemen \\ Anestesiologi dan Terapi Intensif Fakultas Kedokteran Universitas Gadjah Mada, Rumah Sakit Dr. Sardjito \\ Yogyakarta, ${ }^{* * * *}$ Departemen Anestesiologi dan Terapi Intensif Fakultas Kedokteran Universitas Jenderal Achmad \\ Yani Cimahi Bandung,
}

\begin{abstract}
Abstrak
Kraniofaringioma merupakan tumor otak jinak dengan karakteristik kistik dan kalsifikasi, yang letaknya dikeliingi oleh stuktur vital sehingga sulit untuk dilakukan reseksi total. Terapi kombinasi dengan Gamma knife radiosurgery (GKRS) merupakan pilihan terapi paling tepat. Prosedur GKRS yang kompleks meliputi banyak tahap dengan durasi 6-10 jam, memerlukan pemberian anestesi pada pasien yang tidak kooperatif. Kasus ini mengenai pasien anak perempuan berusia 4 tahun dengan cystic craniopharyngioma. Pasien dengan keluhan pandangan mata buram, dari pemeriksaan fisik didapatkan papil atrofi bilateral. Hasil magnetic resonance imaging (MRI) menunjukkan massa tumor yang menekan kelenjar hipofise inferior. Pasien menjalani prosedur GKRS selama 6 jam dengan anestesi sedasi sedang menggunakan Propofol $75 \mathrm{mcg} / \mathrm{kg} / \mathrm{menit}$. Hemodinamika selama prosedur stabil, tidak terjadi komplikasi. Pemilihan teknik anestesi dapat berupa anestesi umum atau sedasi, tergantung pada kondisi pasien, dokter anestesi, operator, dan fasilitas. Pertimbangan anestesi pada GKRS antara lain prosedur dilakukan di luar kamar operasi, durasi panjang, transportasi ke beberapa tempat seperti radiologi dan cathlab, imobilisasi kepala untuk mencegah pergeseran frame stereotaktik, pasien sendiri di dalam ruang radiasi, prinsip neuroanestesi pediatrik.
\end{abstract}

Kata kunci: kista kraniofaringioma, gamma knife radiosurgery, anestesi di luar kamar operasi, neuroanestesi pediatrik

JNI 2021;10 (2):102-112

\section{Anesthetic Management of Pediatric Patient with Cystic Craniopharyngioma Underwent Gamma Knife Radiosurgery}

\begin{abstract}
Craniopharyngioma is a benign tumor characterized by cystic and calcification, surrounded by vital structures therefor it is difficult to perform total tumor resection. Combination with Gamma knife radiosurgery (GKRS) is the best treatment option. The complexities of GKRS consisting of several phases lasts for 6-10 hours. Anesthesia is needed for uncooperative patients. This is a case of a 4-year-old girl with cystic craniopharyngioma. The patient had chief complaint of blurry vision, physical examinations revealed bilateral papil atrophy. Result of MRI showed tumor mass compressing inferior hypophyse. Patient underwent the procedure under moderate sedation with Propofol at $75 \mathrm{mcg} / \mathrm{kg} / \mathrm{min}$ for 6 hours. Intraoperative hemodynamic condition was stable without adverse events. Choice of anesthesia either general anesthesia or sedation, depends on the condition of patient, considerations from anesthesiologist dan neurosurgeon, dan availability of facilities. Unique considerations for GKRS are; a non-operating room anesthesia, long duration, transportation to other units such as radiology and cathlab, head of the patients need to be immobilized to prevent frame displacement, the patient will be alone in the treatment room, and principles of pediatric anesthesia and neuroanesthesia.
\end{abstract}

Key words: cystic craniopharyngioma, gamma knife radiosurgery, non-operating room anesthesia, pediatric neuroanesthesia

JNI 2021;10 (2): 102-112

This article is licensed under

Creative Commons Attribution-NonCommercial-ShareAlike 4.0 International License.

CMonika Widiastuti, Radian A. Halimi, Iwan Fuadi, Sri Rahardjo, Tatang Bisri

(2021) under the CC-BY-NC-SA license 


\section{Pendahuluan}

Kraniofaringioma merupakan tumor otak jinak, ekstra aksial, memiliki karakteristik kistik dan kalsifikasi, yang berasal dari kantong Rathke. ${ }^{1}$ Kraniofaringioma memiliki insidens 0,13 dari 100.000 , berkontribusi sebesar $7,8 \%$ dari tumor otak pada anak, $5-10 \%$ dari tumor otak pada orang dewasa. ${ }^{1}$ Kraniofaringioma biasa ditemukan pada pasien dengan dua distribusi usia, yakni 5-14 tahun dan 50-74 tahun. ${ }^{2}$ Gejala yang biasa ditemukan adalah gejala akibat penekanan di struktur sekitarnya, seperti gangguan penglihatan akibat tertekannya nervus optikus dan kiasma optikus, gangguan hormonal akibat pengaruh pada kelenjar pituitari, serta hidrosefalus obstruktif. ${ }^{1,2}$

Meskipun termasuk tumor jinak dan pertumbuhannya lambat, tumor ini memiliki tantangan besar bagi dokter bedah saraf dikarenakan karakteristiknya yang kistik dan berada di sekeliling struktur-struktur vital serta memiliki angka rekurensi yang tinggi. ${ }^{1,3}$ Penanganan harus disesuaikan dengan klinis dan kondisitumorsetiappasien, dapatdilakukanreseksi tumor parsial, terapi radiasi, ataupun kemoterapi (intrakistik). Terapi radiasi salah satunya adalah dengan Gamma Knife Radiosurgery (GKRS). ${ }^{1-3}$ Prosedur GKRS menggunakan Cobalt 60 sebagai sumber radiasi yang menghasilkan sinar Gamma yang bekerja merusak kromosom dan cairan intrasel dari sel tumor. ${ }^{3}$ Keuntungan dari prosedur GKRS adalah dapat meradiasi tumor dengan efek samping minimal pada struktur di sekitar tumor. Tidak seperti operasi tradisional, GKRS tidak menyebabkan terjadinya infeksi, hematoma, kebocoran dari cairan serebrospinal, facial weakness, hilangnya pendengaran, dan cidera pada struktur vital sekitar tumor., ${ }^{2,3}$

Prosedur GKRS sendiri terdiri dari beberapa tahapan mulai dari pemasangan frame stereotaktik di kepala sampai ke terapi radiasi. Durasi prosedur dapat berlangsung 6-10 jam dan berpindah-pindah lokasi. Pada pasien yang tidak kooperatif seperti pasien anak, pemberian anestesi diperlukan. ${ }^{4}$ Untuk prosedur GKRS, pertimbangan anestesinya adalah anestesi dilakukan di luar kamar operasi, durasi yang panjang, berpindah lokasi dalam kondisi pasien dengan frame stereotaktik yang terpasang, dan pasien akan berada sendiri di dalam ruang GKRS. Pada pasien anak, perbedaan fisiologis dan farmakologis dengan orang dewasa, juga menjadi pertimbangan bagi dokter anestesi. Pertimbangan neuroanestesi juga penting dilakukan. ${ }^{5}$

Pertimbangan anestesi lainnya adalah gangguan hormonal akibat pengaruh pada kelenjar pituitari, seperti gangguan pada adrenocorticotropic hormone (ACTH), growth hormone (GH), gonadotropin, dan thyoid stimulating hormone (TSH) juga diabetes insipidus yang dapat mempengaruhi kadar elektrolit. Oleh karena itu penilaian dan optimalisasi dari gangguan hormonal yang dialami pasien harus dilakukan sebelum operasi. ${ }^{6,7}$ Anestesi pada GKRS dapat berupa anestesi lokal pada anak remaja atau dewasa, pembiusan umum dengan intubasi endotrakeal atau sedasi. Pemilihan anestesi tergantung pada kondisi klinis pasien, dokter anestesi, operator, dan fasilitas yang tersedia di rumah sakit. Sedasi dapat menjadi pilihan pada institusi yang fasilitasnya kurang mendukung. Obat anestesi pilihan adalah Propofol kontinyu yang dititrasi sesuai dengan kondisi hemodinamika pasien. ${ }^{8}$ Evaluasi pre-operasi dan koordinasi yang baik antar bagian sangat penting untuk menunjang kelancaran selama prosedur karena prosedur akan berlangsung lama, dilakukan di luar kamar operasi dan akan ada mobilisasi ke unit lainnya. ${ }^{6}$

\section{Kasus}

\section{Anamnesis}

Pasien anak perempuan berusia 4 tahun, berat badan $22 \mathrm{~kg}$, tinggi badan $90 \mathrm{~cm}$ dengan keluhan pandangan kabur sejak 3 bulan sebelum masuk rumah sakit, diketahui dengan perilaku pasien yang sering menabrak barang yang ada di depannya dan terjatuh saat berjalan. Pasien baru pertama kali mengalami keluhan ini, tidak ada riwayat kejang, penurunan kesadaran, muntah proyektil, sakit kepala, kelemahan anggota gerak. Tidak ada gejala peningkatan frekuensi urinasi ataupun jumlah urine yang banyak. Tidak ada riwayat serupa dalam keluarga. Pasien 
melakukan konsultasi ke dokter spesialis mata dan dirujuk ke dokter spesialis bedah saraf.

\section{Pemeriksaan Fisik}

Pemeriksaan fisik menunjukkan pasien compos mentis, tekanan darah (TD) 110/60 mmHg, laju nadi $80 \mathrm{x} /$ menit, laju pernapasan $18 \mathrm{x} /$ menit, suhu tubuh $36,2^{\circ} \mathrm{C}$. Pemeriksaan jalan napas, pasien dapat membuka mulut lebih dari 3 jari, dapat melakukan fleksi, tidak ada hipertrofi tonsil dan Mallampati 1. Pemeriksaan toraks, abdomen, ekstremitas, dalam batas normal. Pemeriksaan neurologis dalam batas normal. Pemeriksaan mata didapatkan visus Oculo Dextra 1/60, Oculo Sinistra $0,5 / 60$, gerakan bola mata bebas ke segala arah, reflex cahaya turun Oculo Dextra dan Sinistra, papil atrofi ODS.

\section{Pemeriksaan Penunjang}

Hasil laboratorium pasien tertera pada Tabel 1. Hasil pemeriksaan Magnetic Resonance Imaging (MRI) kepala menunjukkan massa kistik dengan dinding berkalsifikasi di suprasella retrochiasma berukuran $3,3 \times 3 \times 3,2 \mathrm{~cm}$ yang menonjol ke intraselladanmenekankelenjarhipofise keinferior. Struktur intrakranial lain dalam batas normal. Tidak tampak infark akut, perdarahan, maupun malformasi vaskular intrakranial. (Gambar 1,2) Pasien direncanakan oleh tim bedah saraf untuk dilakukan pemasangan Omaya Reservoir dikarenakan karakteristik tumornya yang kistik dilanjutkan dengan terapi gamma knife sebanyak 1 sesi, 1 minggu pascaoperasi. Selama 1 minggu pascaoperasi pasien mengeluh pandangan mata tetap kabur, tidak ada sakit kepala, muntah, kejang atau gejala neurologis lainnya. Mobilisasi dan asupan makan minum pasien baik.

\section{Pengelolaan Anestesi}

Untuk persiapan tindakan gamma knife, pasien dipuasakan selama 6 jam. Cairan infus D51/4NS $60 \mathrm{~mL} / \mathrm{jam}$ diberikan. Rencana anestesi sedasi sudah dijelaskan kepada keluarga pasien. Monitor tekanan darah (TD), elektrokardiogram (EKG), $\mathrm{SpO}_{2}$ dipasang. Oksigen 3 Liter/menit diberikan melalui nasal kanula. Pemeriksaan fisik awal didapatkan tekanan darah 108/55 $\mathrm{mmHg}$, laju nadi 90x/menit, EKG sinus ritme,

Tabel 1. Hasil Laboratorium Pasien

\begin{tabular}{llll}
\hline Parameter & Hasil & Unit & Nilai Normal \\
\hline Hemoglobin & 13,9 & $\mathrm{~g} / \mathrm{dL}$ & $10,7-14,2$ \\
Hematokrit & 38,4 & $\%$ & $31-43$ \\
Eritrosit & 4,69 & $106 / \mu \mathrm{L}$ & $3,7-5,7$ \\
Leukosit & 5,9 & $103 / \mu \mathrm{L}$ & $5-15,5$ \\
Trombosit & 321 & $103 / \mu \mathrm{L}$ & $150-440$ \\
Natrium & 139 & $\mathrm{mmol} / \mathrm{L}$ & $137-145$ \\
Kalium & 4,3 & $\mathrm{mmol} / \mathrm{L}$ & $3,6-5,0$ \\
Klorida & 97 & $\mathrm{mmol} / \mathrm{L}$ & $98-107$ \\
Ureum & 20 & $\mathrm{mg} / \mathrm{dL}$ & $<50$ \\
Kreatinin & 0,31 & $\mathrm{mg} / \mathrm{dL}$ & $0,5-1,1$ \\
PT kontrol & 11,10 & detik & $9,1-12,3$ \\
PT pasien & 10,50 & detik & $9,4-11,3$ \\
INR & 0,97 & & \\
APTT kontro & 31,5 & detik & $27,7-37,5$ \\
APTT pasien & 42,4 & detik & $27,7-40,2$ \\
Gula Darah Sewaktu & 85 & $\mathrm{mg} / \mathrm{dL}$ & $<200$ \\
\hline
\end{tabular}

Keterangan: $\mathrm{PT}=$ Prothrombin Time, $\mathrm{INR}=$ International Normalized Ratio, APTT $=$ Activated Partial Thromboplastin Time 


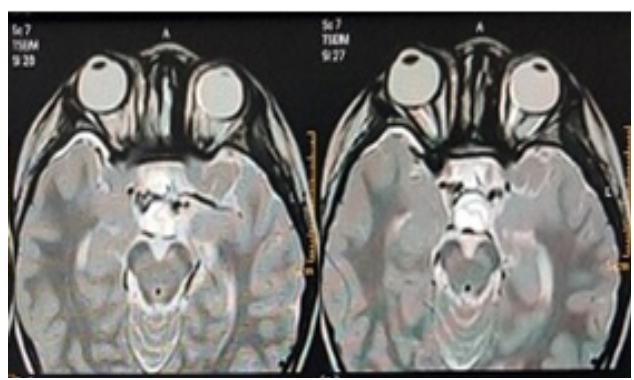

Gambar 1. Foto MRI yang menunjukkan massa cystic craniopharyngioma pasca pemasangan Omaya Reservoir (panah kuning)

laju pernapasan $20 \mathrm{x} /$ menit, suhu tubuh $36,1^{\circ} \mathrm{C}$. Sedasi dimulai sebelum pemasangan frame stereotaktik di kepala; dengan memberikan fentanyl $1 \mathrm{mcg} / \mathrm{kg}$ iv bolus, propofol $2 \mathrm{mg} /$ $\mathrm{kg}$ iv bolus. Anestesi lokal dengan kombinasi Lidokain $2 \%$ dan Epinephrine sebanyak $4 \mathrm{mg} /$ $\mathrm{kg}$, diinjeksikan di 4 titik di scalp; saraf greater occipital bilateral dan saraf supraorbital bilateral, dimana pin untuk fiksasi frame akan dipasang. Dilakukan aspirasi cairan kista sebanyak 8 $\mathrm{mL}$ melalui Omaya Reservoir. Setelah frame selesai dipasang, dilakukan pengukuran cranium untuk keperluan planning treatment. Propofol kontinyu diberikan dengan dosis $75 \mathrm{mcg} /$ $\mathrm{kg} / \mathrm{min}$ selama tindakan pemasangan frame. Setelah frame terfiksasi dengan baik, dilakukan MRI kepala untuk konfirmasi koordinat lesi tumor. Prosedur MRI berlangsung selama 50 menit dengan rumatan anestesi menggunakan propofol $75 \mathrm{mcg} / \mathrm{kg} / \mathrm{min}$ iv kontinyu. Hemodinamika selama MRI stabil, tekanan darah 90-100/60-70

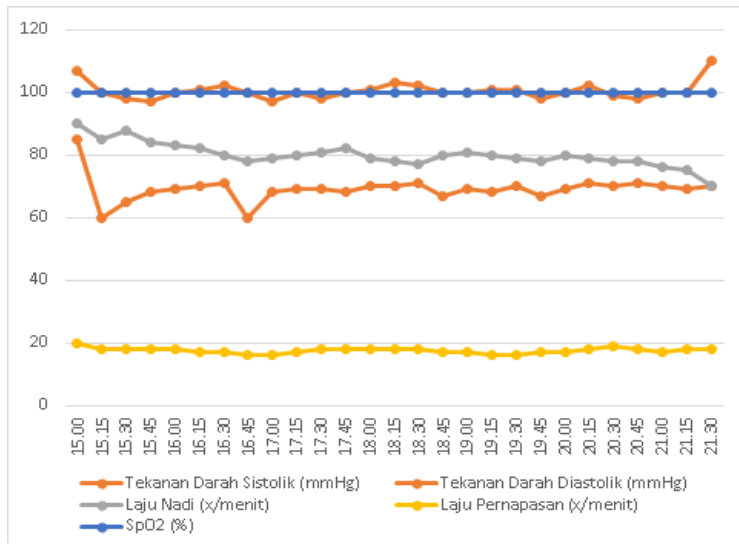

Grafik 1. Hemodinamika Pasien Selama Prosedur
$\mathrm{mmHg}$, laju nadi $70-85 \mathrm{x} /$ menit, laju pernapasan 16-20 x/menit, $\mathrm{SpO}_{2} 100 \%$ dengan $\mathrm{O}_{2} 3$ Liter/ menit.

Setelah MRI selesai pasien kembali ke ruang persiapan, sementara operator melakukan planning treatment terapi, pasien tetap dalam anestesi menggunakan propofol kontinyu dosis $75 \mathrm{mcg} / \mathrm{kg} / \mathrm{min}$ dan dilakukan pemasangan kateter urin. Hasil planning treatment didapatkan durasi terapi selama 101 menit dengan dosis 14 Grey. Pasien kemudian dibawa ke ruang terapi, prosedur time out dilakukan. Propofol kontinyu dosis $75 \mathrm{mcg} / \mathrm{kg} / \mathrm{min}$ diberikan selama tindakan, cairan rumatan menggunakan D51/4NS $40 \mathrm{~mL} /$ jam. Hemodinamika pasien selama prosedur sejak pemasangan frame, MRI, planning treatment, dan terapi stabil, TD 100-110/60-70 $\mathrm{mmHg}$, laju nadi $70-90 \mathrm{x} / \mathrm{menit}$, laju pernapasan 14-18 $\mathrm{x} /$ menit, EKG sinus ritme, $\mathrm{SpO}_{2} 100 \%$. Urine output sekitar $50 \mathrm{~mL} / \mathrm{jam}$. Total durasi prosedur selama 6 jam. (Gambar 3. Grafik Hemodinaika Pasien Selama Prosedur)

\section{Pengelolaan Pascabedah}

Setelah selesai, pasien dibawa ke ruang persiapan untuk diobservasi. Terapi medikamentosa pasca GKRS yaitu ketorolak $0,5 \mathrm{mg} / \mathrm{kg}$ iv bolus, omeprazole $2 \mathrm{mg} / \mathrm{kg}$ iv bolus, deksametason 0,5 $\mathrm{mg} / \mathrm{kg}$ iv bolus, ondansteron $0,15 \mathrm{mg} / \mathrm{kg}$ iv bolus. Pasien stabil selama masa pemulihan anestesi,

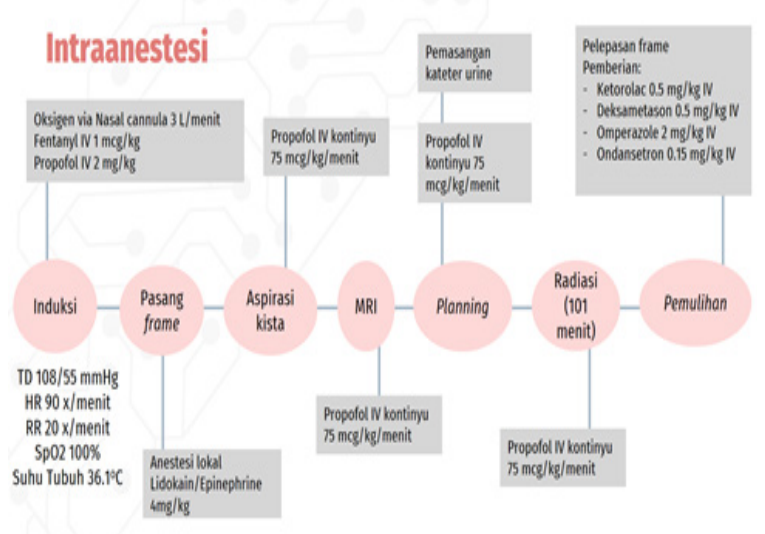

Gambar 2. Tahapan Intraanestesi pada Pasien. Prosedur berlangsung selama 6 jam dimulai dari tahap induksi hingga pelepasan frame 
dengan tekanan darah $110 / 70 \mathrm{mmHg}$, laju nadi 70x/menit, laju napas 16x/menit, $\mathrm{SpO}_{2} 100 \%$ room air, suhu $36^{\circ} \mathrm{C}$. Saat pasien sudah sadar, orientasi baik tidak sakit kepala, tidak mual dan muntah, pasien diperbolehkan kembali ke ruang perawatan. Pasien stabil selama di ruangan dan diperbolehkan pulang di hari ketiga pascaprosedur.

\section{Pembahasan}

Kraniofaringioma merupakan tumor otak jinak dan pertumbuhannya lambat. Karakteristiknya yang kistik dan kalsifikasi, serta dapat menginvasi struktur sekitarnya, menjadi tantangan bagi dokter bedah saraf. Terapi ideal adalah reseksi tumor total, akan tetapi hal ini sulit dilakukan karena letak tumor itu sendiri yang dapat menginvasi pituitary stalk, hipotalamus, jaras optik dan pembuluh darah sekitar. ${ }^{3}$

Kraniofaringioma memiliki angka rekurensi yang tinggi dan beberapa sekuele dari terapi yang berupa gangguan endokrin, gangguan penglihatan, komplikasi metabolik, defisit kognitif dan psikososial yang pada akhirnya menurunkan kualitas hidup pasien., ${ }^{1,3}$ Pilihan terapi untuk melakukan reseksi ulang sering menjadi pertimbangan untuk memilih terapi lain yang lebih tidak invasif, karena itu dikombinasi dengan terapi radiasi, seperti GKRS. ${ }^{1,3}$ Gamma knife stereotactic radiosurgery dicetus pada tahun 1950, Borje Larsson dan Lars Leksell memulai investigasi untuk mengkombinasi proton beams dan alat stereotaktik yang mampu untuk mencapai target spesifik dalam otak. Cobalt 60 adalah radioaktif yang digunakan sebagai sumber radiasi. Cobalt 60 akan terurai menjadi elektron dan sinar gamma, sinar Gamma inilah yang kemudian digunakan untuk terapi radiasi. Dengan menggunakan GKRS, sinar Gamma akan diarahkan secara spesifik terhadap lesi dengan dosis tertentu. Sinar Gammabekerja menyebabkan apoptosis sel tumor dengan merusak kromosom dan cairan intrasel dari sel tumor. ${ }^{3}$ Prosedur GKRS dapat dilakukan dalam satu sesi atau beberapa sesi, tergantung jenis, ukuran, dan lokasi tumor. Satu sesi GKRS dapat berlangsung 6-10 jam dikarenakan terdiri dari berbagai tahapan; dimulai dari pemasangan frame, pemeriksaan radiologi seperti Magnetic Resonance Imaging (MRI), Computed Tomography (CT) scan, atau Digital Substraction Angiography (DSA), planning treatment treatment, dan terapi radiasi. ${ }^{3}$ Pada umumnya, orang dewasa yang kooperatif menjalani GKRS dengan anestesi lokal pada saat pemasangan frame stereotaktik. Akan tetapi pada beberapa populasi pasien, seperti pasien anak, pasien klaustrofobia, atau pasien dengan penyulit lainnya, diperlukan pendampingan dokter anestesi. $^{4}$

Kraniofaringioma terletak di regio sellar atau suprasellar, dikelilingi oleh banyak struktur penting seperti traktus optikus, kiasma optikus, kelenjar pituitari. Gejala klinis yang dialami pasien terjadi akibat penekanan atau invasi tumor ke struktur sekitar. Anamnesis, pemeriksaan fisik dan penunjang harus dilakukan secara komprehensif untuk mengetahui permasalahan neurologi dan hormonal yang dialami pasien. ${ }^{6,7}$

Pasien dapat mengalami gangguan akibat efek massa dan peningkatan tekanan intrakranial sehingga mengakibatkan nyeri kepala dan mual muntah, serta permasalahan hormonal seperti diabetes insipidus yang mengakibatkan gangguan elektrolit dan gangguan pada adrenocorticotropic hormone (ACTH), growth hormone (GH), gonadotropin, dan thyoid stimulating hormone (TSH). Oleh karena itu penilaian dan optimalisasi dari gangguan hormonal yang dialami pasien harus dilakukan sebelum operasi. ${ }^{6,7}$ Pada pasien ini, gejala yang ditemukan adalah gejala gangguan penglihatan. Tidak tidak ditemukan adanya gejala nyeri kepala, mual-muntah, kejang, peningkatan frekuensi dan volume urinasi yang mengarah ke diabates insipidus dan gangguan elektrolit, pasien juga tidak dalam riwayat penggunaan steroid, pasien tidak memiliki tanda gigantisme atau menunjukkan adanya tanda pubertas primer. Pada pemeriksaan penunjang, sebaiknya dilakukan pemeriksaan hormonal seperti hormon ACTH, TSH dan kadar kortisol. Pemeriksaan elektrolit dilakukan pada pasien ini dan hasilnya normal. Pada pasien dengan diabetes insipidus sering ditemukan kondisi hipernatremia dengan gejala dehidrasi karena poliuria. ${ }^{6,7}$ Anestesi pada 
yang menjalani GKRS mempunyai beberapa pertimbangan, yakni anestesi dilakukan di luar kamar operasi, durasi lama, berpindah-pindah tempat, posisi frame stereotaktik tidak boleh berubah, dan pasien sendirian di dalam ruang GKRS. $5,8,10$

Untuk prosedur GKRS dapat dilakukan anestesi umum dengan intubasi endotrakeal atau sedasi. ${ }^{5,8} \mathrm{Ada}$ beberapa pustaka yang menyebutkan anestesi umum dengan intubasi endotrakeal menjadi pilihan dalam GKRS pada anak karena durasi yang lama dan keberadaan frame stereotaktik akan membuat anak tidak nyaman, ditambah dengan risiko pergerakan kepala pasien dapat menyebabkan dislokasi dari frame stereotactic. ${ }^{5,11}$ Akan tetapi, ada juga yang melaporkan keberhasilan anestesi pada prosedur GKRS dengan sedasi. ${ }^{4,8}$ dengan pertimbangan kompleksitas prosedur yang harus berpindah tempat. Tatalaksana anestesi pada pasien yang akan menjalani GKRS meliputi evaluasi preoperasi, intraoperasi, dan pascaoperasi. Pemilihan teknik anestesi umum atau sedasi kembali ke pertimbangan dokter anestesi, operator, dan fasilitas di rumah sakit. Di rumah sakit, idealnya di setiap ruang tindakan yang membutuhkan anestesi terdapat oksigen outlet di dinding yang memudahkan pemberian oksigen, juga adanya ventilator atau mesin anestesi yang mobile dan kompatibel terhadap MRI. ${ }^{5,11}$ Akan tetapi, karena keterbatasan fasilitas, dipilih teknik anestesi sedasi untuk pasien ini.

Evaluasi preoperasi dilakukan pada pasien yang akan menjalani prosedur GKRS sama seperti evaluasi preoperasi pada umumnya, ditambah dengan pertimbangan neuroanestesi. Pada kasus pasien dengan tumor otak maka perlu dilakukan evaluasi sebagai berikut:

\section{Anamnesis}

- Kondisi pasien saat ini, apakah terdapat gejala peningkatan TIK seperti nyeri kepala, mual, muntah, penglihatan buram. Apakah terdapat riwayat kejang. Jika terdapat defisit neurologis fokal: defisit motorik atau sensorik akibat penekanan massa.

- Obat-obatan yang dipakai apakah pasien mendapatkan terapi steroid (deksametason), obat kejang, mannitol, atau obat lainnya. Karena hal ini berhubungan dengan kontinuitas dari obat dan interaksi obat dengan agen anestesi.

- Bagaimana status hidrasi pasien untuk melihat kecukupan asupan cairan dan efek pemberian diuretik.

- Apakah pasien pernah mempunyai riwayat operasi bedah saraf (redo atau bukan).

- Apakah terdapat komorbiditas lainnya yang menyertai

- Apakah terdapathipertrofi tonsil atau kelainan anatomi jalan napas untuk pertimbangan dilakukannya sedasi. ${ }^{12}$

\section{Pemeriksaan Fisik}

- Meliputi pemeriksaan status mental, level kesadaran, adanya papil edema, respons Cushing (hipertensi, bradikardia), skor GCS, defisit fokal12

- Pemeriksaan tanda gigantisme, pubertas primer, atau gejala hormonal lainnya. ${ }^{6,7}$

\section{Pemeriksaan Penunjang}

- Pemeriksaan radiologik (CT scan atau MRI): Harus dievaluasi ukuran dan lokasi tumor (apakah dekat dengan pembuluh darah besar atau area eloquent otak), adanya efek massa berupa midline shift, herniasi temporal atau frontal, hilangnya basal CSF cisterna, hidrosefalus. Pada pasien ini, massa sudah menekan kelenjar hipofisis ke inferior. ${ }^{12}$

- Pemeriksaan laboratorium untuk melihat hemoglobin, platelet, kadar elektrolit, fungsi ginjal. Pada kasus kraniofaringioma, perlu dilakukan pemeriksaan hormonal seperti $\mathrm{ACTH}, \mathrm{GH}$, gonadotropin, TSH untuk menilai fungsi endokrin yang mungkin terpengaruh akibat tumor. ${ }^{6}$

Selain melakukan informed consent mengenai pemilihan teknik anestesi, juga diberikan informasi mengenai tahapan prosedur. Koordinasi antar bagian radiologi dan ruang gamma knife harus dipersiapkan sehingga meminimalisir waktu tunggu untuk masing-masing prosedur dikarenakan pasien dalam posisi teranestesi. Ada beberapa tahapan dalam prosedur GKRS: ${ }^{3}$ 


\section{Tahap Pertama}

Tahap ini meliputi pemasangan frame stereotaktik. Operator menginjeksikan lokal anestesi di titik pin frame akan dipasang. Pada kasus ini, lokal anestesi yang diberikan adalah lidokain dengan campuran epiefrin. Penambahan epinefrin dapat memperpanjang masa kerja lokal anestesi sehingga adekuat untuk prosedur yang berlangsung lama. Penggunaan bupivakain dengan durasi yang lebih lama juga dapat digunakan untuk fasilitasi pemasangan pin. ${ }^{11,13}$ Tahap ini adalah salah satu tahap paling penting karena saat frame terpasang jika posisi kepala tidak tepat, dapat menyebabkan obstruksi jalan napas dan akan sulit untuk mengamankan jalan napas, melakukan ventilasi ataupun intubasi. Peralatan yang dibutuhkan untuk melepas frame dan peralatan emergensi harus selalu berada di dekat pasien. Jika gangguan jalan napas terjadi dan perlu dilakukan pelepasan frame, maka koordinasi dan resimulasi ulang tahapan-tahapan prosedur GKRS harus dilakukan.

\section{Tahap Kedua}

Tahap kedua adalah pemeriksaan MRI atau CT Scan untuk menentukan koordinat tumor dalam frame stereotaktik. Untuk prosedur MRI perlu diingat mengenai medan magnet dalam ruang MRI yang membatasi peralatan medis yang dapat dibawa ke dalam ruang MRI. Oksigen yang tertanam di dinding akan menjadi pilihan terbaik jika fasilitas rumah sakit memungkinkan. ${ }^{14}$

Pada pasien yang terintubasi, perlu dipilih mesin anestesi dan peralatan intubasi yang kompatibel terhadap MRI. Monitor yang kompatibel dengan MRI juga diperlukan. Menggunakan total intravenous anesthesia (TIVA) juga menggunakan syringe pump atau mesin target-controlled infusion (TCI) yang kompatibel terhadap MRI. ${ }^{14}$ Adanya keterbatasan fasilitas dimana tidak terdapat syringe pump yang kompatibel terhadap MRI, maka pemanjangan selang infus menjadi pilihan pada kasus ini. Posisi frame disesuaikan dengan coil khusus gamma knife agar tidak hiperektensi atau hiperfleksi untuk mencegah obstruksi jalan napas. Selama proses transportasi dari ruang GKRS ke tempat lain, posisi jalan napas pasien, kondisi silinder Oksigen dan baterai dari monitor, ventilator, dan syringe pump harus diperhatikan. ${ }^{15}$

\section{Tahap Ketiga}

Tahap ketiga adalah planning treatment treatment oleh operator. Pada tahapan ini dosis radiasi dihitung sehingga didapatkan dosis radiasi yang sesuai untuk lesi tumor dan dosis radiasi yang aman untuk struktur vital sekitar tumor dan jaringan otak normal. Prosedur ini membutuhkan waktu yang lama dan pasien harus tetap dalam kondisi teranestesi. Pada pasien ini, pasien ditempatkan di ruang ruang persiapan dengan tetap terpasang oksigen 3 Liter/ menit, monitor, dan dalam propofol kontinyu.

\section{Tahap Keempat}

Tahap keempat adalah terapi radiasi. Pada tahap ini pasien akan mendapat terapi GKRS sesuai dengan dosis yang sudah dikalkulasi operator. Pasien akan berada sendirian di dalam ruang GKRS. Operator, dokter anestesi, dan petugas medis lainnya akan mengawasi pasien melalui kamera yang terpasang di ruangan. ${ }^{3}$

Sebelum terapi dimulai, harus diperhatikan posisi kepala agar tidak hiperekstensi atau hiperfleksi untuk mencegah obstruksi jalan napas dan bahu pasien diberikan bantalan untuk mencegah ketegangan pada otot-otot. Posisi lengan dan bagian-bagian tubuh lain yang merupakan pressure point juga harus diperhatikan. Selang pernapasan, selang infus maupun kateter harus difiksasi dengan baik karena tempat tidur GKRS akan bergerak mengikuti proses radiasi sinar gamma. ${ }^{3}$ Kamera harus difokuskan pada jalan napas pasien, pergerakan dada, abdomen, sumber oksigen, mesin anestesi atau ventilator, monitor, syringe pump, dan tiang infus. Volume dari monitor $\mathrm{SpO}_{2}$ harus dapat terdengar melalui kamera dan gelombang dari parameter EKG, $\mathrm{SpO}_{2}, \mathrm{ETCO}_{2}$, pernapasan harus jelas terlihat di kamera. ${ }^{3}$ Terapi radiasi akan berjalan secara otomatis sesuai durasi yang sudah dikalkulasi. Dalam kondisi gawat darurat, terapi radiasi dapat dihentikan dengan menekan tombol shutoff. Keberadaan tombol ini harus diketahui, akan tetapi perlu diingat adanya tenggat waktu untuk 
radiasi berhenti, yakni selama 3 menit. Peralatan emergensi dan alat untuk melepaskan frame harus selalu tersedia di dekat ruang terapi GKRS. ${ }^{8}$

\section{Tahap Kelima}

Pascaoperasi, frame kepala akan dilepaskan. Analgetik diberikan untuk mengurangi nyeri di scalp. Pada pasien ini diberikan Ketorolac intravena. Penggunaan ketorolac intravena pada pasien bedah saraf masih kontroversial. Termasuk dalam golongan antiinflamasi non-steroid (AINS), ketorolac bekerja dengan menghambat siklooksigenase 1 dan 2 yang berpengaruh pada fungsi trombosit dan memperpanjang waktu perdarahan. Oleh karena pengaruhnya pada kaskade koagulasi dan risiko menyebabkan perdarahan, maka ketorolac dihindari pada pascaoperasi. Pemberian obat selektif penghambat siklooksigenase 2, sperti parecoxib diteliti aman digunakan pada prosedur bedah saraf. ${ }^{13}$ Akan tetapi, ada beberapa penelitian yang menunjukkan ketorolac aman diberikan pada pasien anak yang menjalani prosedur bedah saraf. ${ }^{16}$ Mual muntah pascaoperasi merupakan hal yang paling sering dikeluhkan, karena itu ondansetron diberikan pada pasien ini. Steroid deksametason juga diberikan untuk mengurangi edema otak. ${ }^{5,8}$

Prosedur anestesi di luar kamar operasi menjadi sesuatu yang rutin seiring perkembangan dunia medis, akan tetapi diperlukan latihan khusus karena berada di luar zona aman, yakni kamar operasi. Dokter anestesi harus menghadapi tantangan berada di lokasi baru, monitor yang tidak adekuat, staff asisten yang kurang terlatih,

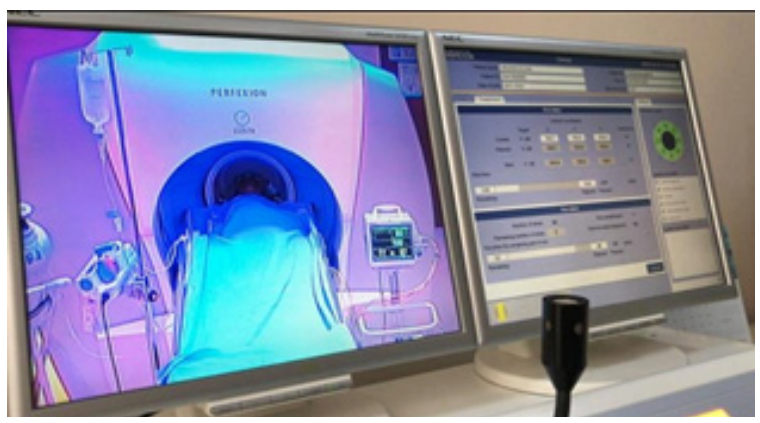

Gambar 3. Contoh pengawasan pasien, monitor, oksigen, syringe pump, infus, melalui kamera yang terpasang di dalam ruang Gamma Knife Center Indonesia kurang familiar dengan prosedur yang dilakukan, dan kurangnya pengalaman sehingga dapat mempengaruhi kualitas dari pelayanan anestesi Pilihan anestesi pada prosedur di luar kamar operasi dapat berupa sedasi ataupun anestesi umum. ${ }^{11,14}$

Pada kasus ini, pertimbangan anestesi pediatrik harus diterapkan karena anak berbeda secara anatomi, fisiologis dan farmakologis dengan orang dewasa. ${ }^{8}$ Secara anatomi, besar kepala pasien biasanya melebihi Secara neurofisiologi, pasien anak berbeda dengan pasien dewasa, cairan serebrospinal pada anak (90-100 mL/100 $\mathrm{g} /$ menit) lebih banyak daripada orang dewasa $(50 \mathrm{~mL} / 100 \mathrm{~g} /$ menit). Kebutuhan Oksigen untuk metabolisme $\left(\mathrm{CMRO}_{2}\right)$ lebih tinggi pada anak $(5,2 \mathrm{~mL} / 100 \mathrm{~g} / \mathrm{menit})$ lebih tinggi dari orang dewasa $(3,5 \mathrm{~mL} / 100 \mathrm{~g} /$ menit $)$. Oleh karena itu, pasien anak lebih rentan terhadap iskemia akibat hipoksia dibandingkan orang dewasa. Autoregulasi juga ada di pembuluh darah otak anak dan variasi yang berlebihan pada tekanan darah dapat menyebabkan risiko terjadinya iskemia otak atau perdarahan intraventrikel. Tekanan darah rerata (MAP) pada pasien anak dijaga sekitar 50-65 mmHg, tekanan perfusi otak (CPP) $40-50 \mathrm{mmHg} .{ }^{7,8}$

Meskipun pemilihan teknik anestesi adalah sedasi, pertimbangan ABCDE neuroanestesi tetap harus dilakukan pada pasien ini. ${ }^{12}$ Airway (A), jalan napas harus bebas sepanjang waktu. Pada pasien ini, meskipun bernapas spontan tanpa bantuan oral atau nasal airway, tidak terjadi obstruksi jalan napas. Lama puasa pasien harus dikonfirmasi dikarenakan pasien akan tetap bernapas spontan selama sedasi. Pemilihan nasal cannula pada pasien ini karena ukuran frame yang tidak memungkinkan untuk pemasangan sungkup wajah.

Breathing (B), pasien ini bernapas secara spontan dengan suplementasi Oksigen $3 \mathrm{~L} /$ menit melalui nasal cannula. Meskipun anestesi sedasi, idealnya kapnografi kontinyu digunakan sebagai alat monitoring dari pasien ini..$^{15,17}$ Tujuan penggunaan kapnografi adalah selain untuk mengukur $\mathrm{ETCO}_{2}$ juga untuk menilai pertukaran 
gas secara kontinyu, apakah pernapasan pasien normal, hipopnea, atau bahkan apnea. Karena jika sedasi terlalu dalam, akan menyebabkan hipoventilasi atau apnea yang menyebabkan hiperkarbia sehingga menyebabkan peningkatan aliran darah otak dan tekanan intrakranial. ${ }^{15}$ Akan tetapi karena keterbatasan alat monitoring dan tidak tersedianya nasal cannula yang memiliki port untuk kapnografi, maka monitoring $\mathrm{ETCO}_{2}$ tidak dilakukan. Saat tindakan, dipastikan napas spontan dengan laju napas adekuat dan tidak terdapat obstruksi jalan napas. ${ }^{8,15}$

Circulation (C): target dari sirkulasi adalah normotensi dengan mencapai MAP dan CPP sesuai usia pasien anak untuk menjaga autoregulasi serebral. Pada pasien ini MAP target sekitar 50-65 mmHg, CPP 40-50 $\mathrm{mmHg}$ dan normovolemia dengan tidak menggunakan cairan yang tidak mengandung dextrose dan cairan hipotonik. ${ }^{17}$ Manajemen cairan pada pasien bedah saraf anak menjadi tantangan karena perbedaan patofisiologi, sensitivitas terhadap hilangnya cairam, ketidakmampuan untuk menilai adekwat atau tidak karena keterbatasan monitoringm dan pertimbangan puasa jangka waktu lama, akan tetapi pemberian dextrosa pada pasien bedah saraf tidak direkomendasikan. Cairan isotonik menjadi pilihan untuk mencegah kenaikan tekanan intrakranial dan menjaga perfusi otak. Pemberian dextrosa tambahan tidak direkomendasikan, pemeriksaan gula darah dilakukan berdasarkan klinis masing-masing pasien. ${ }^{18}$ Elevasi kepala 30o tidak dapat dilakukan karena tempat tidur GKRS yang mengharuskan pasien berbaring secara datar. Posisi kepala dalam posisi netral, sehingga tidak terjadi obstruksi vena jugularis.

Drugs (D): Hindari obat-obat dan teknik anestesi yang meningkatkan tekanan intrakranial, berikan obat yang mempunyai efek proteksi otak. Pada pasien ini obat yang diberikan adalah fentanyl dan propofol. Kortikosteroid, deksametason diberikan untuk mengurangi edema vasogenik yang berhubungan dengan tumor.

Environment (E): Normotermia atau mild hipotermia harus dijaga. Pireksia merupakan vasodilator yang potent dan meningkatkan
$\mathrm{CMRO}_{2}$ serta metabolisme sistemik sebesar $10 \%$ setiap kenaikan 1 derajat. Propofol menjadi pilihan obat sedasi pada pasien ini. Propofol merupakan obat hipnotik sedatif yang bekerja cepat dan banyak digunakan untuk prosedur yang menimbulkan nyeri atau tanpa nyeri. Onset cepat, waktu pemulihan yang singkat, mudah untuk dititrasi, mempunyai properti antiemetik, dan memiliki potensi yang reliable untuk membuat sedasi dalam, menjadikan propofol sebagi agen yang banyak dipilih untuk sedasi di luar kamar operasi. Oleh karena properti ini, propofol menjadi pilihan untuk sedasi pada anak, melalui pemberian secara bolus atau kontinyu. ${ }^{19}$

Pada kasus GKRS, propofol harus diberikan secara kontinyu untuk mencegah pasien bergerak. Dengan dosis 25-75 $\mathrm{mcg} / \mathrm{kg} / \mathrm{min}$, pasien dapat menjalani prosedur dengan stabil tanpa terjadi komplikasi. Propofol tidak memilik properti analgesia, maka kombinasi dengan Fentanyl diperlukan pada prosedur menyebabkan nyeri, seperti saat pemasangan pin head frame. 8 Efek samping propofol yang banyak menjadi pertimbangan dokter anestesi adalah depresi pernapasan dan hipotensi. ${ }^{11,15}$ Pada tahun 2009 terdapat publikasi artikel yang melibatkan 49.386 pasien dalam sedasi yang dilakukan oleh dokter emergensi pediatrik dan pediatrik intensivis. Didapatkan bahwa komplikasi terjadi sebesar 5,92\% dengan komplikasi terbesar adalah obstruksi jalan napas dan desaturasi. Akan tetapi komplikasi ini dapat tertangani dengan melakukan perubahan posisi kepala, jaw thrust atau menaikkan aliran oksigen. Terdapat 103 pasien yang membutuhkan intubasi endotrakeal. Hal ini menunjukkan bahwa propofol aman digunakan jika dokter yang memberikan mengetahui properti farmakokinetik dan farmakodinamik obat dengan tepat dan mampu melakukan tatalaksana jalan napas. ${ }^{19}$

Pada pasien ini, sedasi berhasil dilakukan secara aman, tanpa episode obstruksi jalan napas, desaturasi, dan agitasi. Teknik anestesi dengan sedasi sedang menggunakan propofolIV kontinyu. Akses intravena yang lancar harus dipastikan dalam teknik sedasi dengan obat intravena kontinyu. ${ }^{15,17}$ Selain propofol, ada obat lain yang 
dapat digunakan sebagai obat pilihan sedasi pasien anak di luar kamar operasi, seperti pentobarbital, dan dexmedetomidine. Pentobarbital dihindari karena efek depresi kardiovaskular dan respirasi. Dexmedetomidine dapat dengan aman digunakan pada pasien anak, yang menjadi pertimbangan adalah onset dan pemulihan yang lebih lambat dibandingkan propofol serta efek bradikardia. Akan tetapi, risiko desaturasi dan depresi napas pada pemberian dexmedetomidine lebih rendah daripada pemberian propofol. ${ }^{20}$ Sedasi yang dilakukan pada pasien ini adalah sedasi sedang (moderate), yang definisinya adalah keadaan depresi kesadaran setelah terinduksi obat dimana pasien dapat berespon terhadap perintah verbal atau stimulasi taktil ringan. Tidak diperlukan intervensi terhadap jalan napas, napas spontan masih adekuat. Fungsi kardiovaskular terjaga. Pada sedasi sedang ini, harus diperhatikan agar pasien tidak menjadi ke tahap sedasi dalam atau anestesi umum, karena refleks atau patensi jalan napas seringkali hilang dan fungsi ventilasi terganggu. ${ }^{15,17}$

Penggunaan Ramsay Sedation Scale (RSS) digunakan untuk menilai kedalaman sedasi secara objektif. Target kedalaman sedasi adalah Ramsay Skala 4-5. Berikut adalah skala dari RSS: cemas dan agitasi atau tidak tenang atau keduanya; kooperatif, terorientasi, tenang; hanya berespon terhadap perintah; respon cepat terhadap ketukan ringan pada glabella (dahi) atau terhadap stimulus auditorik; respon lambat terhadap ketukan ringan pada glabella (dahi) atau terhadap stimulus auditorik keras; tidak ada respon Setelah prosedur selesai, pasien akan dibawa ke ruang pemulihan. Observasi pasca pemberian sedasi di luar kamar operasi tetap dilakukan seperti di post anesthesia care unit (PACU). ${ }^{15,17}$ Analgetik, antiemetik dan kortikosteroid diberikan kepada pasien. Pasien biasanya akan pulang dua sampai tiga hari pasca tindakan jika tidak terjadi komplikasi.

\section{Simpulan}

Gamma knife radiosurgery adalah pilihan terapi kombinasi pada kraniofaringioma karena komplikasi yang minimal. Prosedur GKRS yang terdiri dari beberapa tahapan sangat membutuhkan kerja sama yang baik dari pasien. Pada pasien anak yang tidak kooperatif dibutuhkan anestesi untuk prosedur ini. Pertimbangan anestesi pada prosedur ini antara lain anestesi dilakukan di luar kamar operasi, durasi panjang, berpindah lokasi dalam kondisi pasien dengan frame stereotaktik yang terpasang, dan pasien akan berada sendiri di dalam ruang GKRS, prinsip anestesi pediatrik dan neuroanestesi. Anestesi umum merupakan pilihan yang aman mengingat kompleksitas prosedur dan durasi yang panjang, namun jika fasilitas tidak mendukung, sedasi dapat menjadi pilihan anestesi. Persiapan obat dan peralatan anestesi yang lengkap, koordinasi baik, dan familiaritas dengan prosedur, evaluasi preoperasi secara holitstik, penerapan prinsip anestesi pediatrik dan neuroanestesi, dapat menunjang keberhasilan anestesi sedasi menggunakan propofol kontinyu pada prosedur ini.

\section{Daftar Pustaka}

1. Patnaik A, Mahapatra AK. Role of gamma knife radiosurgery in craniopharyngioma. Indian J Neurosurg. 2013;2(03):256-61.

2. Jensterle M, Jazbinsek S, Bosnjak R, Popovic M, Zaletel LZ, Vesnaver TV, dkk. Advances in the management of craniopharyngioma in children and adults. Radiol Oncol. 2019;53(4):388-96.

3. Padmapriya B, Subhashini N, Natarajan P, Rajeshwari TK. Treatment planning of gamma knife and stereotactic radiosurgery in brain tumor. Dalam: 2011 International Conference on Process Automation, Control and Computing. IEEE; 2011.1-4.

4. Hasegawa H, Kamata K, Hayashi M, Komayama N, Kawamata T, Ozaki M. Can pediatric gamma knife radiosurgery be managed under monitored anesthesia care? A case presentation and proposal from anesthesiologists. J Radiosurgery SBRT. 2019;6(3):235.

5. Schecter WS. Gamma knife radiosurgery. Dalam: Sun LS, Houck P, Hache M, editors. 
Handbook of Pediatric Anesthesia. New York: Lange; 2014, 267-70.

6. Bajwa SJS, Bajwa SK, Bindra GS. The anesthetic, critical care and surgical challenges in the management of craniopharyngioma. Indian J Endocrinol Metab. 2011;15(2):123.

7. Nezar AZ, Haroun MA, Mounir MA, Hamada MA, Okasha MM. Anesthetic considerations for craniopharyngioma resection in pediatric patient with fontan physiology: a case Report. J Anesth Clin Res. 2017;8(716):2.

8. Edler A. Special anesthetic considerations for stereotactic radiosurgery in children. J Clin Anesth. 2007;19(8):616-8.

9. Edala T, Koka R, Koka B V. Radiation therapy. In: Soriano SG, McClain CD, editors. Essentials of Pediatric Neuroanesthesia. Cambridge: Cambridge University Press; 2019. hlm 153-8.

10. Harris EA. Sedation and anesthesia options for pediatric patients in the radiation oncology suite. Int J Pediatr. 2010; 1-9.

11. Bisri T, Bisri DY. ABCDE Neuroanestesi Prinsip dan Teknik. Dalam: Anestesi untuk Operasi Tumor Otak Supratentorial dan Infratentorial. Bandung: Fakultas Kedokteran Universitas Padjajaran; 2016. 1-40.

12. Vadivelu N, Kai AM, Tran D, Kodumudi G, Legler A, Ayrian E. Options for perioperative pain management in neurosurgery. J Pain Res. 2016;9:37.

13. Youn AM, Ko Y-K, Kim Y-H. Anesthesia and sedation outside of the operating room. Korean J Anesthesiol. 2015;68(4):323.

14. Coté CJ, Wilson S. Guidelines for monitoring and management of pediatric patients before, during, and after sedation for diagnostic and therapeutic procedures: update 2016. Pediatr Dent. 2016;38(4):13E-39E.
15. Maxwell LG, Buckley GM, Kudchadkar SR, Ely E, Stebbins EL, Dube C, dkk. Pain management following major intracranial surgery in pediatric patients: a prospective cohort study in three academic children's hospitals. Pediatr Anesth. 2014;24(11):113240.

16. Amercican Society of Anesthesiologists. Continuum of depth of sedation: definition of general anesthesia and levels of sedation/ analgesia. Illinois; 2014 [Diperbarui 15 Oktober 2014, diunduh 8 November 2020]. Tersedia dari: https://www.asahq.org/ standards-and-guidelines/continuum-ofdepth-of-sedation-definition-of-generalanesthesia-and-levels-of-sedationanalgesia/.

17. Lee JK, Brady KM. Developmental cerebrovascular physiology. Dalam: Soriano $\mathrm{SG}$, McClain CD, editor. Essentials of Pediatric Neuroanesthesia. Cambridge: Cambridge University Press; 2019, 9-14.

18. Karnik HS. Fluid management in infants and children during intracranial surgery. $\mathrm{J}$ Neuroanaesth Crit Care. 2017;4(04):S24-9.

19. Cravero JP, Beach ML, Blike GT, Gallagher SM, Hertzog JH, Consortium PSR. The incidence and nature of adverse events during pediatric sedation/anesthesia with propofol for procedures outside the operating room: a report from the Pediatric Sedation Research Consortium. Anesth Analg. 2009;108(3):795-804.

20. Sulton C, McCracken C, Simon HK, Hebbar $\mathrm{K}$, Reynolds J, Cravero J, dkk. Pediatric procedural sedation using dexmedetomidine: a report from the Pediatric Sedation Research Consortium. Hosp Pediatr. 2016;6(9):53644. 